\title{
Petrophysical rock typing and permeability prediction in tight sandstone reservoir
}

\author{
Anita Lis-Śledziona ${ }^{1} \mathbb{C}$
}

Received: 4 May 2019 / Revised: 23 July 2019 / Accepted: 21 August 2019 / Published online: 29 August 2019

(C) The Author(s) 2019

\begin{abstract}
In this paper, the low-permeability reservoir was subdivided into several units based on three models; in the first model, porosity, permeability, pore sizes, and shale volume were used as an input in the heterogeneous rock analysis clustering workflow to define rock units; in the second model, rock types were defined using flow zone index. The third flow unit discriminator was proposed by the author; the model is based on relation between porosity, permeability, irreducible water saturation, and pore size distribution. Also, Wyllie-Rose equation for permeability in tight reservoir was core-calibrated, and coefficients $e, d$, and $\mathrm{Kw}$ were established. The reservoir is built of thin layers of sandstones with variable porosity, permeability, pore sizes, and irreducible water. The research was performed in two wells where as input well log data, the laboratory results of mercury injection porosimetry, permeability measurements, and nuclear magnetic resonance data were used. Furthermore, it was investigated whether the presence of fractures identified on XRMI images were strictly related to one flow unit.
\end{abstract}

Keywords Rock typing · Hydraulic flow units · Tight gas formation · Flow zone index (FZI) · Heterogeneous rock analysis (HRA) · Permeability prediction

\section{Introduction}

Reservoir rock typing drives the quality of the distribution of petrophysical parameters in three (3D) Earth models and is crucial to reservoir characterization. It provides a better understanding of fluid flow, rock storage capacity, and pore size distribution. Classification of rock types can be based on many different criteria. A process of rock typing classifies reservoir rocks into distinct units, each of which was deposited under similar geological conditions and undergone similar diagenetic alteration (Guo et al. 2005). Fluid flow and saturation characteristics in a reservoir rock are the crucial parameters that control the quality of reservoir rock and need to be considered in reservoir rock typing (Aliakbardoust and Rahimpour-Bonab

The paper was presented at the CAGG 2019 Conference "Challenges in Applied Geology and Geophysics" organized at the AGH University of Science and Technology, Krakow, Poland, 10-13 September 2019.

Anita Lis-Śledziona

lis@ @inig.pl

1 Oil and Gas Institute - National Research Institute, Lubicz 25 A, 31-503 Kraków, Poland
2013). It is also important to recognize the structure and texture of tight, reservoir rocks using the novel approach to known methods-laboratory and well logging (Zhu et al. 2018; Puskarczyk et al. 2018; Zhang et al. 2018). This study presents rock typing with an understanding of petrophysical properties such as porosity, pore size, permeability, and capillary water content. The analyses of flow parameters changes were performed in low-porosity and low-permeability sandstone formation being considered as the transition reservoir between tight and conventional. The gas in such rocks was formed outside the reservoir and migrated into the reservoir over millions of years. Many of these kinds of formations are hydraulically fractured to enhance production. In these low-permeability layered systems, the petrophysicists and geologists usually need more core-measured, laboratory data to evaluate the reservoir. To balance the need for more data with the need to minimize costs, the best solution is to spend money gathering data on a few wells and then use correlations developed from that data to evaluate the uncored wells that will be drilled thereafter. Poorly recognized reservoirs properties can have a significant impact in reservoir performance predictions. (Guo et al. 2005) in his article describes how rock typing can be an effective tool for water saturation and 
permeability modeling. Many relationships between core and well log data might be noticed once the reservoir is grouped according to their rock types (porosity-permeability, wettability-irreducible water saturation). When most sands are deposited, the pores and pore throats are well connected, resulting in high permeability. Sands are composed of mineral particles called grains, which usually consist of quartz, feldspars, and rock fragments (Berg 1986). The original porosity and permeability of a sandstone are determined by characteristics such as mineral composition, pore type, grain size, and texture. After deposition and burial, the grains and matrix are commonly altered by the physical effects of compaction and by chemical changes. These changes are broadly referred to as diagenesis which has a strong impact on the reduction in primary porosity and permeability and primary high permeability formation becomes tight, low-porosity rock.

The analyzed reservoir has thickness of several dozen meters and is not homogenous as the crucial flow parameters change with depth and a seemingly homogeneous formation is very diverse in terms of the possibilities of media flow, and it also has a complex pore structure. There was laboratory data of mercury injection porosimetry performed in two wells. Nuclear magnetic resonance tests were also done. This measurement method, carried out on fluid saturated rock samples, provide useful information to characterize their pore structure. The examinations reflect general sensitivity of NMR measurements on pore size distribution, which is of particular significance in applications used in petroleum geology (Dullien 1992). Routine application of NMR data during well log interpretation enables evaluation of reservoir properties of rocks includes total and effective porosity and irreducible water saturation. Two wells were the subject of reservoir evaluation in order to recognize and describe the fluid flow and accumulation ability properties and propagate the correlation between results of core measurements and well $\log$ data to the other uncored wells in the reservoir. The shale volume in the interpreted boreholes was calculated and calibrated with the XRD data from the neighboring well. Porosity, permeability, irreducible water saturation, and the pore sizes are considered as four main factors for investigation of the reservoir quality. Based on the calculated and core-calibrated flow properties, the reservoir was subdivided into four units of different media flow and gas storage capacities. The reservoir quality was determined by three different models. The third model of tight reservoir-grading method was proposed by the author. A typical tight gas reservoir is a layered formation, the values of reservoir properties should be determined on layer-by-layer basis. By developing multilayer models, better completions are achieved for this kind of reservoirs.

\section{Rock type prediction models: description}

Heterogeneous sandstone is actually divided into intervals characterized by different reservoir properties. The most significant are the changes in permeability, which are closely related to the size of the pores forming the pore space of the rock and affect the capillary water content. For the efficient tight reservoir exploitation and planning of possible fracturing processes, it is crucial to accurately determine the depth of the horizons with the best reservoir properties and flow capabilities. In the literature, there were many different rock type classification models presented, and the author tested three models to find the best indicator of different flow unit in tight formation (Jiang et al. 2015; Ilkhchi et al. 2014). The first model was based on the heterogeneous rock analysis (HRA) clustering workflow to define rock units. Heterogeneous rock analysis (HRA) is the module of Schlumberger Techlog software 2015.3 that was used to perform the cluster analysis. In the first step of the workflow, the data are analyzed using principal component analysis (PCA) and ensures that they are independent (Hotelling 1933; Pearson 1901). This solution is simply a geometric rotation in a multidimensional space that locks onto the orthogonal axes of relative elongation in a cloud of data points (Doveton 1994). Then cluster analysis is run to find the uniqueness based on a similar set of measurements and create the HRA classification. The goal of the $k$-means clustering is to minimize the distance between each data point and the center of each defined cluster and to maximize the distance between the centroid of each cluster (Duenas 2014). Well log data-shale volume (VCL), pore sizes $(P)$ together with porosity (PHIE), and permeability $(K)$-were used as an input in this method. The first attempt was to use the raw well logs as the inputs, but the results, subdivided into units, did not refer to flow properties of the rock but were rather related to electrofacies which are numerical combinations of petrophysical log responses that reflect specific physical and compositional characteristics of a rock interval.

The second method was based on flow zone index (FZI) presented by Amaefule et al. (1993). Flow zone indicator is a unique and useful value to quantify the flow character of a reservoir and offers a relationship between petrophysical properties at small scale (core plugs) and large scale (wellbore level). In addition, the term of FZI provides the representation of the flow zones based on the surface area and tortuosity (Alhashmi et al. 2016).

$\mathrm{FZI}=\frac{\mathrm{RQI}}{\mathrm{PMR}}$,

where reservoir quality index: RQI $=0.0314 \sqrt{\frac{K}{\mathrm{PHIE}}}$ and pore-to-matrix ratio $\mathrm{PMR}=\frac{\mathrm{PHIE}}{1-\mathrm{PHIE}}$.

$K$ is permeability in $\mathrm{mD}$, and PHIE is porosity in fraction. 
The third flow unit discriminator tight reservoir quality index (TRQI) was proposed by the author. The proposed model is based on relation between porosity (PHIE), permeability $(K)$, capillary water saturation (SWIc, in fraction), and size of the pores forming the pore space of the rock $(P$ in micrometers).

TRQI $=\frac{P * \sqrt{\frac{K}{\text { PHIE }}}}{\text { SWIc }}$.

The research was performed in two wells where as input well $\log$ data, the laboratory results of mercury injection porosimetry (MIP), permeability measurements, and Nuclear Magnetic Resonance (NMR) data were used.

The comparison of laboratory-measured and well logcalculated porosity, permeability, and pore size distribution in each subdivided unit were done for validation and assessment of the most appropriate method to use in the tight formation.

\section{Input data calculation}

\section{Geological settings}

Cambrian sandstones which are the subject of interpretation consist predominantly of fine-grained, moderately sorted, and well-rounded quartz arenites. Micas, feldspar, chert, and heavy minerals comprise together below $5 \%$ of the rock content. Clay cement and detrital clay matrix are also present in Cambrian sandstones (Sikorska and Pacześna 1997). The rocks can be considered as mineralogically very mature. Quartz cement completely or partly fills pore spaces and is one of the main causes of porosity loss in Cambrian sandstone reservoirs in the Baltic Basin (Laškova 1987). Toward the deeper buried parts of the basin in west Lithuania, the amount of quartz cement increases. The geometry of pore space, described usually by the parameter such as pore size distribution, connectivity between the pores, shape, and pore orientation, controls the reservoir characteristics. The main type of pore is a primary intergranular pore reduced mainly by quartz overgrowths. In strongly quartz-cemented samples, small remnant primary pores occur isolated and disconnected. Samples with porosity lower than $5 \%$ have negligible permeability, below $1 \mathrm{mD}$. Secondary pores do occur, and they are oversized pores which are typical feature for secondary porosity. They are related to post-depositional leaching of detrital grains. The dissolution of mineral components will lead to redistribution of pore space and change in pore size distribution, but not necessarily to an increase in porosity, since dissolution may lead to precipitation of authigenic minerals elsewhere in the system (Molenaar et al. 2007).

\section{Permeability and porosity modeling}

Permeability is the ability of fluid to move through the pores and is a measure of the ease with which fluids pass through the rock. Thus, it is extremely important to know the values of formation permeability and porosity in every rock layer. The values of permeability control important reservoir processes from gas flow rate to fracture fluid leak-off. It is impossible to determine the location of the perforations, the length of the hydraulic fracture, and the conductivity of the hydraulic fracture, if one does not know the values of formation permeability. To determine the values of formation permeability, well log data, cores, production tests, and prefracture pressure buildup tests or injection falloff tests can be used. Tight formations are considered to be reservoirs with an absolute permeability of less than $10 \mathrm{mD}$ and can range down to microdarcy (Speight 2017). At the microscopic scale, porosity and permeability are highly dependent on the geometry of the pores and pore throats within the homogeneous system. These microscopic, locally homogeneous domains are usually found as layered sediments or clusters which confer different degrees of heterogeneity (Radlinski et al. 2004). Drilling success in any reservoir is dependent on finding the most prospective areas, or the sweet spot and aligning the wellbore for maximum borehole exposure to these zones. Permeability prediction has always been and still is one of the most critical aspect of a static and dynamic model. The direct measurement primarily comes from core data. Thus far, no wireline logging tool has been capable of measuring permeability directly. Core analysis provides a varied menu of solutions to the reservoir modeling and is used for reservoir description (Keelan 1982).

In this work, the permeability $(K)$ was calculated based on modified Wyllie-Rose Eq. (3) (Wyllie and Rose 1950) and calibrated with core-measured data. The Wyllie-Rose relationship is a generalized equation that requires the determination of values for the constants e, d, and Kw. Probably, the most widely used version of this equation is the "Timur equation" for sandstones. Timur (1968) developed an equation which linked permeability with both porosity and irreducible water saturation SWI in sandstones, based on laboratory measurements of cores. The permeability values in the interpreted wells range from 0.001 to $3.5 \mathrm{mD}$. The permeability curve obtained from this equation was used as an input in first and third method in rock clustering process. The calibration process was done just to obtain the general trend of permeability changes. We need to bear in mind that we deal with unconventional reservoir and the laboratory-measured permeability might not be accurate for very low-permeability samples. The permeability was also 
calculated using empirical relation between core-measured porosity and permeability. The correlation established on core plugs was used to calculate continuous curve of permeability using porosity (PHIE) calculated from well log data. Such calculated permeability shows good agreement with the data obtained from Wyllie-Rose equation.

$K=\mathrm{Kw} * \frac{\mathrm{PHIE}^{d}}{\mathrm{SWIc}^{e}}$,

Core-calibrated constant values; $\mathrm{Kw}=20, e=2$, and $d=2$.

Two trends of relation between measured porosity and permeability are visible in Fig. 1. Fracture porosity can be recognized by high core permeability despite the low values of measured core porosity and pore sizes. The fractures were also recognized on Xtended Range Micro Imager (XRMI) images. The reservoir represents dual-porosity system.

The pore system is the main controlling parameter in static and dynamic properties of reservoir rock. The values of core-measured effective porosity using mercury porosimetry (MIP) method range from 0.08 to $9 \%$. The porosity curve (PHIE) was obtained using conventional methods: density-neutron logs and neutron-compressional slowness logs, calibrated with measured porosity data (MIP). Mercury porosimetry method is a widely used technique for the evaluation of porosity of the rock. It is the non-wetting property of mercury combined with its high surface tension, that almost uniquely qualifies it for use in probing pore space. At each surface interface with a liquid, there is surface tension which acts like an elastic membrane contacting the surface until the surface forces are in equilibrium with the forces tending to increase the surface area of the interface. If mercury is placed in contact with a pore opening, the surface tension of the mercury acts along the line of contact with the opening equal in length to the perimeter of the opening and creating a force-resisting entry. The volume of pores in the corresponding size unit is obtained by measuring the volume of mercury that intrudes into the sample material with each pressure change. The volume of mercury that enters pores is measured by a mercury penetrometer (an electrical capacitance dilatometer). The mercury inside the capillary decreases as pressure forces mercury out of the capillary and into the sample, and so is the capacitance. The decrease in capacitance, therefore, is proportional to the volume of mercury leaving the capillary with each change in pressure.

The main issue during calibration process was the lack of correlation between measured and calculated porosity due to the presence of vertical drilling-induced fractures and conductive natural fractures in the upper part of reservoir in Well-2. This is because the measured porosity might not be able to include the fracture porosity while the logs measure the total porosity. The log-calculated porosity (PHIE) includes all matrix porosity without the clay-bound water, while the laboratory-measured porosity include only connected pores. In mercury injection porosity method, both the bulk and pore volume are determined. MIP method measures
Fig. 1 Correlation of core permeability and core effective porosity; color scale is the measured pore size body and is obtained from laboratory measurements MIP, in micrometers
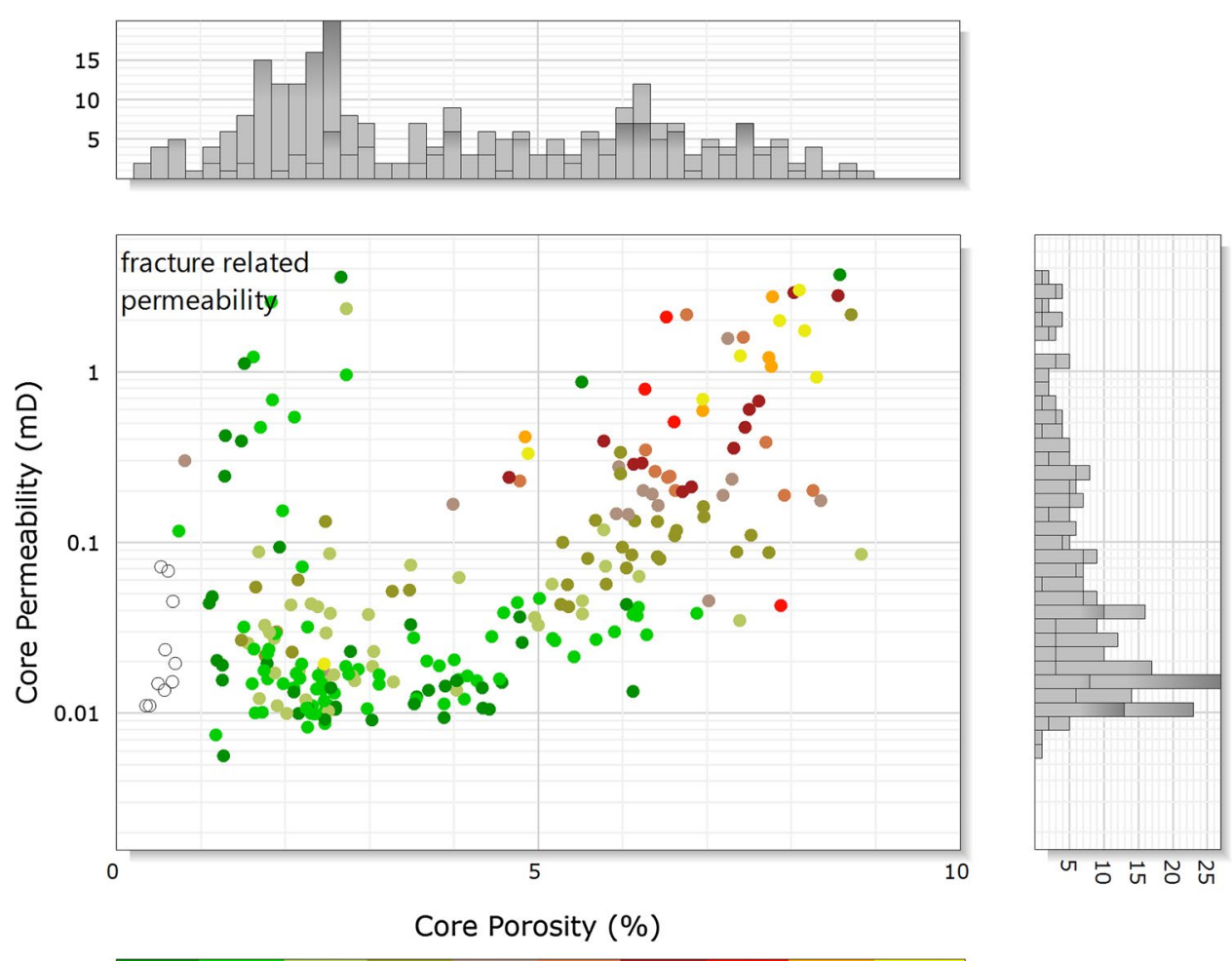

0 PHI_RockPhy (R35 Pore Throat Radius) 1.5 
the porosity of connected pores, as it is impossible to pump mercury into pore which is very small and isolated. Porosity values obtained from MIP are lower than those determined from well log data. This is because at the maximum $\mathrm{Hg}$ injection pressure, of $413 \mathrm{MPa}$, access is possible only to the pores with equivalent pore throat radii larger than $1.8 \mathrm{~nm}$ (Amann and Krooss 2015). In general, the method is not suitable for low-permeability samples as very high pressure is required. Neutron logs determine porosity by assuming that the reservoir pore spaces are filled with either water or oil and then measuring the amount of hydrogen atoms (neutrons) in the pores. These logs underestimate the porosity of rocks that contain gas. Density $\log$ is a porosity log that measures electron density of a formation and determines porosity by evaluating the density of the rocks. Porosity calculated based on density logs in gas-bearing formation overestimates the porosity, and they result in "crossover" of the log curves when paired with neutron logs. The neutron and density $\log$ s are responses to pores of all sizes. The effects of fractures and vugs can be especially seen on the density logs which are very sensitive to the presence of caverns and voids present in the formation.

\section{Pore size distribution}

Pore space of the rock formation is composed of the large number of irregularly shaped and arranged capillaries, which can be filled by reservoir fluids. In petroleum geology, the characterization and description of the physical properties of the pore space depend on the correct determination of transport and storage possibilities of reservoir fluids through the filtration medium. These properties can be assessed by the determination of the porosity coefficient and permeability and also by approximation of the shape and nature of the pore space of this medium with a physical model whose parameters determine the actual filtration and storage properties. The size of the pores is one of the important parameters which should be recognized and estimated during formation evaluation process as it has the major impact on the media flow capacity within the porous rock and should be taken into account during flow units' determination process.

In this paper, pore size distribution curve $(P)$ was calculated based on correlation between core permeability and measured pore sizes forming the pore space of the rock (MIP) (Fig. 2). Description of the pore geometry of reservoirs plays a major role in understanding the degree of pore inter-connectivity and sizes, capillary-trapping potentials, and flow behavior (Bliefnick and Kaldi 1996; Vavra et al. 1992). Hydraulic rock typing demonstrates that permeability is dependent on main pore size. The laboratory measurements and parameterization of the pore space were obtained by capillary pressure curve measurements. In this test, the dependence of the capillary pressure values on the radius, shape, and interconnections between the pores of different radii is used in pore size determination.

\section{Capillary water saturation}

The irreducible water saturation is the sum of capillary-bound water and clay-bound water. The values of PHIE is an effective porosity of the rock, so it was assumed that irreducible water saturation (SWIc) would be mainly capillary-bound water as the clay-bound water is the difference between total and effective porosity. In the conventional reservoirs, generally the pore
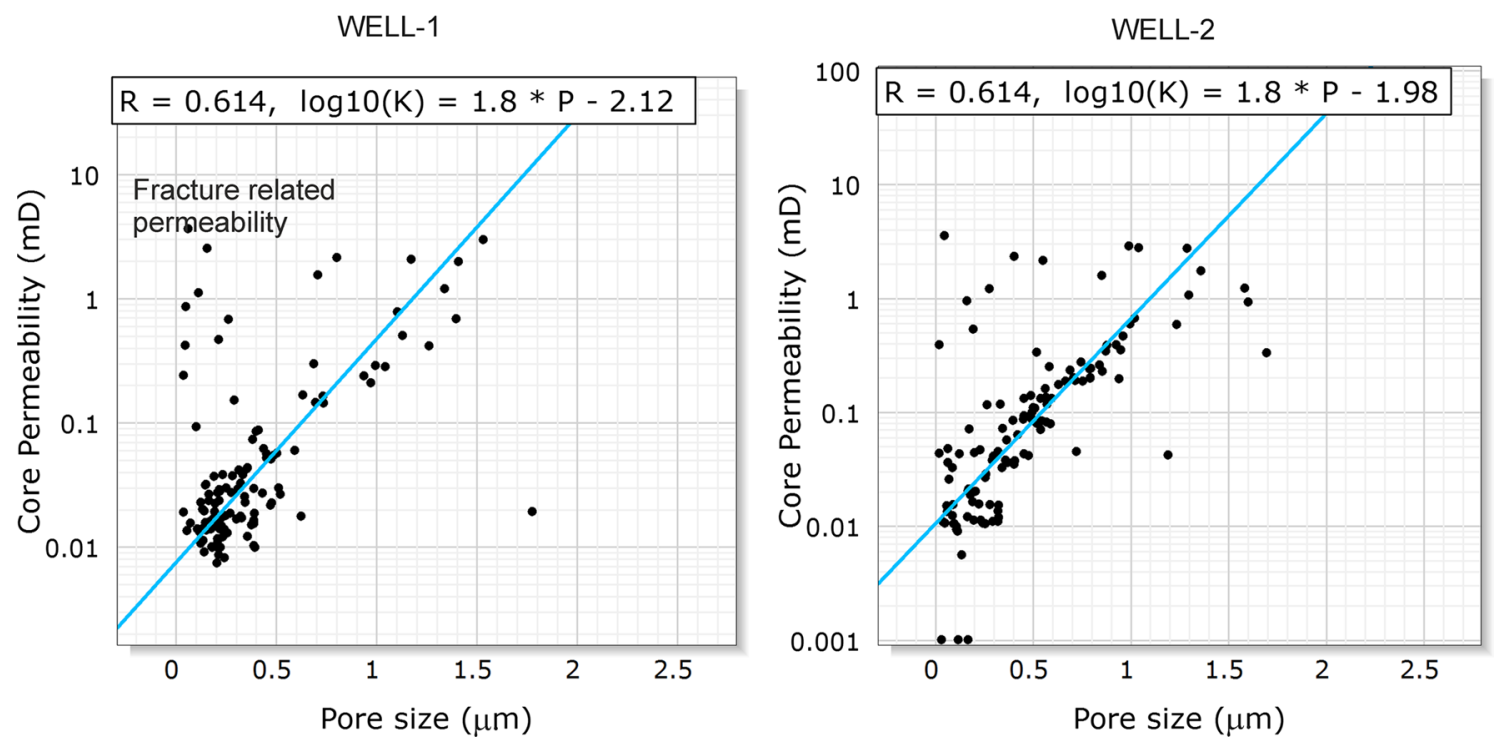

Fig. 2 Correlation of core-measured permeability and pore sizes. In Well-1 the outstanding values are fracture-related. Very high permeability despite the low porosity 
sizes below $1 \mu \mathrm{m}$ are treated as ineffective, occupied by capillary water (Zawisza and Nowak 2012), but in unconventional reservoirs due to higher capillary pressures, certain clusters of pores below $1 \mu \mathrm{m}$ still represent an effective space for gas accumulation (Nelson 2009).

The capillary water content was calculated using two methods, first from the modified Hong's equation (Hong et al. 2017). This is a cross-plot method of capillary water saturation in effective porosity obtain from NMR method (y-axis) with pore structure index $\sqrt{\frac{K}{\text { PHIE }}}$ on $x$-axis. Equation 4 describes the relation between these two variables. Coefficient $a=60$ and $b=-1.74$ were established to get the best fit of Hong's equation to measured data.

SWIc1 $=a * \sqrt[b]{\frac{K}{\text { PHIE }}}$

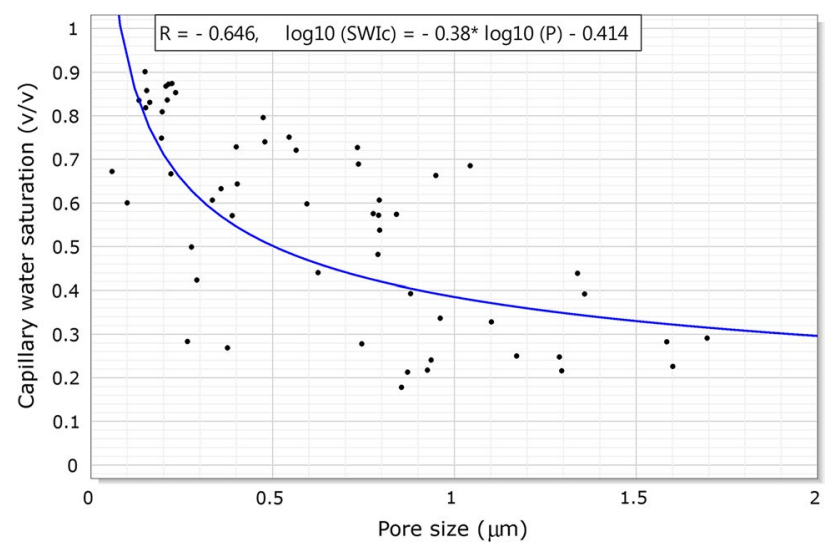

Fig. 3 Correlation of capillary water content obtain from NMR measurements with laboratory-measured pore sizes

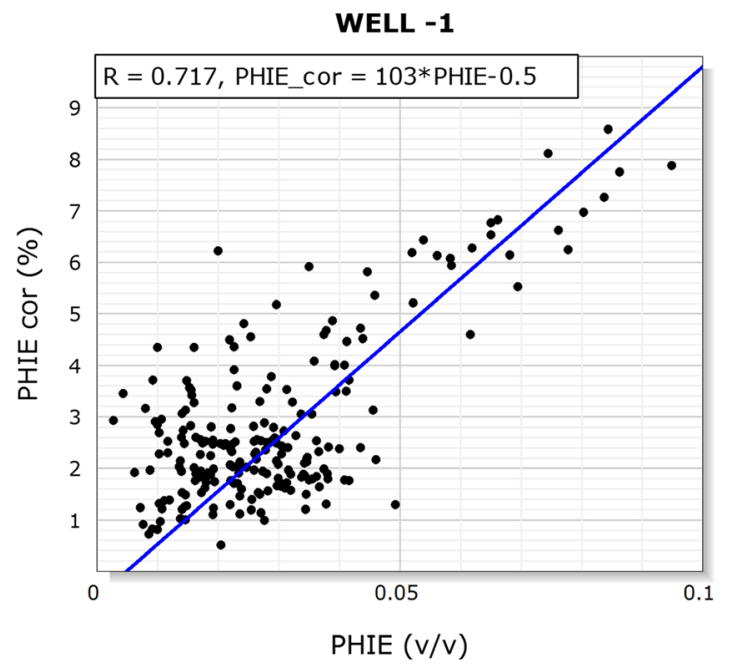

where SWIc1, in percent, stands for capillary water saturation, $K$ is permeability in $\mathrm{mD}$, PHIE is well log-calculated porosity in fraction, $a$ and $b$ are calibration constants (unitless).

Second method was based on correlation between capillary water content from NMR method and pore sizes $(\mu \mathrm{m})$ from MIP measurements (Fig. 3).

$\log 10$ SWIc $2=-0.568 * \log 10(P)-0.52$,

where SWIc2 stands for capillary water saturation and $P$ is pore size in $\mu \mathrm{m}$.

The results from both methods provided similar results, and the final values of SWIc are an arithmetic average from these two methods. Capillary water saturation is high, up to $100 \%$, and in average reaches $80 \%$. This means that most of the water in the formation should be held in the reservoir by capillary forces and that gas production from these rocks should be relatively water-free.

\section{Rock typing and flow unit description}

Core calibration of input data was an important step to obtain correct and accurate data for flow unit determination. Tight gas reservoirs need accurate interpretation of PHIE and $K$ as even small error may have significant impact on reservoir reserves estimation. This process was interrupted mainly in Well-2 by the presence of fractures. In Well-1, good agreement between log-derived and measured porosity was observed (Fig. 4).

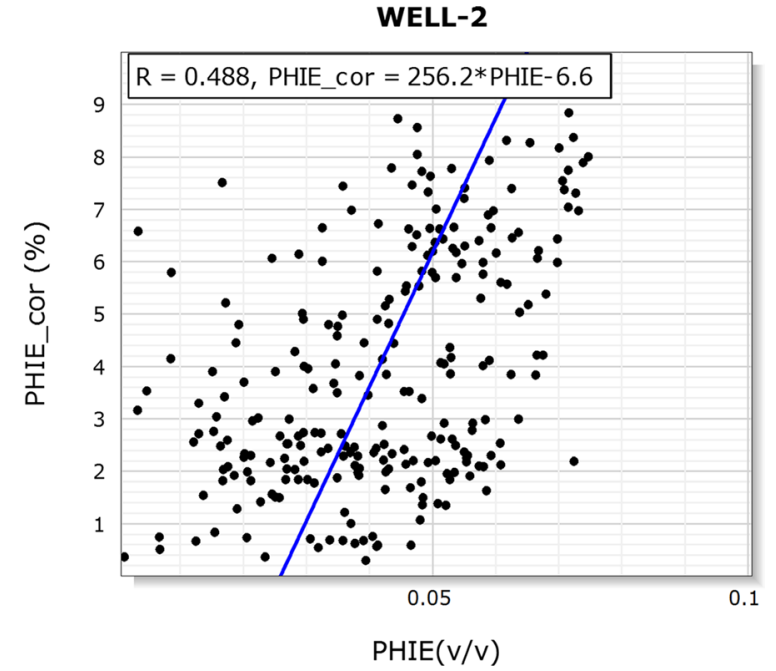

Fig. 4 Correlation of measured (PHIE_cor) and well log-calculated (PHIE) porosity 


\section{The results from HRA method}

Clay volume (VCL) in both wells was calculated using relationship between XRD calibrated clay volume and well $\log$ measurement of thorium concentration in the neighbor wellbore. Based on well log data inputs $(K$, PHIE, $P$ and VCL), four clusters of different fluid flow characteristics have been identified using HRA cluster analysis. The 2D cross-plot presents the first two principal components of the data colored by the cluster chosen and with the center of each cluster displayed on the chart as a gray star (Fig. 5). The variability of the input logs is presented for each unit in a box plot (Fig. 6). The minimum and maximum value for each variable $K$, PHIE, pore size, and VCL is presented in Fig. 6. First unit (dark blue) HRA 1 is characterized by the highest porosity (up to $9.7 \%$ ) and permeability (up to $3.49 \mathrm{mD}$ ) values, low shale volume, and the highest values of pore sizes reaching up to $1.43 \mu \mathrm{m}$, and it is a sub-tight unit. This unit has the best storage and flow capacities. The second unit HRA 2 (light blue) with an average permeability of $0.03 \mathrm{mD}$, effective porosity range from 3 to $7 \%$, and average pore size of $0.25-0.32 \mu \mathrm{m}$ is still potentially a good tight unit. HRA 3 (green color) has similar values of $K$ and PHIE as HRA 2, but it has the highest level of clay volume up to 59\% (Fig. 6). Unit HRA 4 corresponds to impermeable low-porosity sandstones of no accumulation capacity with the lowest level of porosity permeability and pore sizes, and it is a very tight unit (Fig. 7).

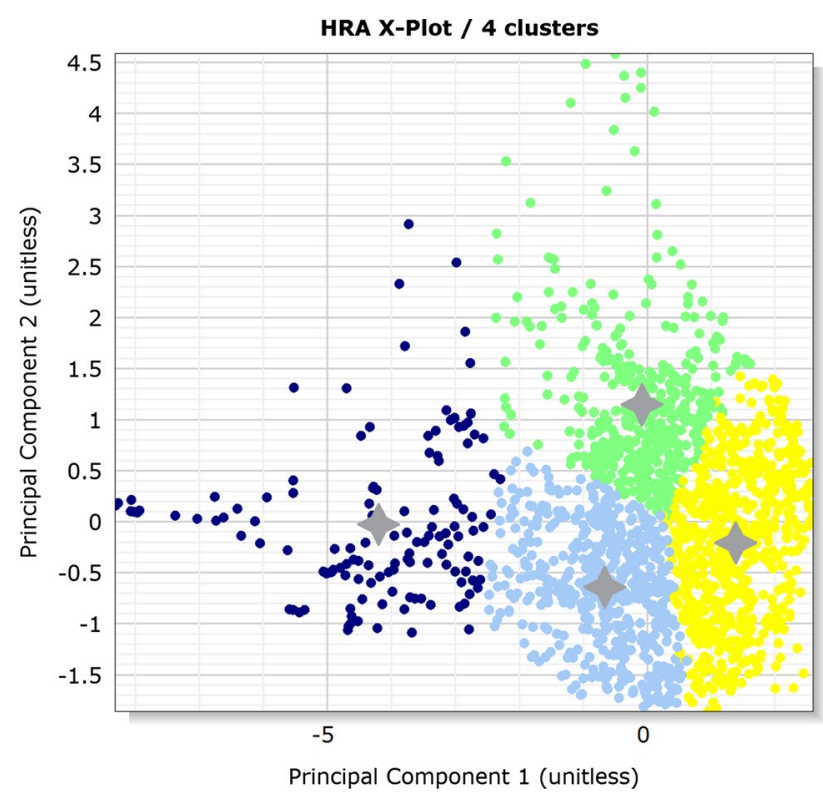

Fig. 5 2D cross-plot of the first two principal components of the data colored by the cluster. HRA 1 is dark blue, HRA 2 is light blue, HRA 3 is green and HRA 4 is yellow

\section{The results from FZI method}

In the second model, the reservoir was subdivided using flow zone index (FZI) (Amaefule et al. 1993). In the first step, FZI was calculated based on laboratory-measured porosity and permeability, according to Eq. 1. In both wells, four flow units were defined and four permeability equations were established. Table 1 presents permeability equations for each unit, and FZI values range for each unit. In the second step, four "zone" permeability curves were calculated in each well based on calculated well log porosity which shows good correlation with measured porosity in Well-1 $R=0.717$ and worse match in Well- $2 R=0.488$ where lots of natural and tensile fractures are seen on XRMI images (Fig. 8). The most important and challenging part of work in this method was to move and apply the relations from core data to well $\log$ data and get the final permeability curve. It was done by fitting the "zone" permeability curves to core data and choosing the one which represents the best fit. Figure 9 present cross-plots of the core-measured porosity and permeability.

Then, the FZI was calculated using well log data and reservoir was subdivided into four units. The FZI unit 1 is marked in dark blue (Fig. 9) and represents the best quality zone where the permeability reaches the highest values, and the permeability decreases in FZI unit 2 and reaches the lowest values in FZI unit 3 . The porosity range is similar for each unit. FZI unit 4 is related to the presence of fractures; it represents the core samples with very high permeability and low porosity, which means that the fluids flow through the existing network of natural and drilling-induced fractures. Figure 10 shows the average values of flow parameters (PHIE, $K, P$ and SWIc) for each FZI unit in interpreted wells. There is no consistency in parameter changing in different flow zones (Fig. 9). In Well-1, average permeability and capillary water content decrease from FZI 1 toward FZI 3 unit; however, porosity and pore sizes increase. That might indicate disconnected/isolated porosity. This shows that FZI method in low-porosity and low-permeability rocks can give the same values of hydraulic units as high porosity and permeability rocks (Aliyev et al. 2016). Therefore, certain rock type can comprise entire range of porosity and permeability, which is not physically reliable. The main issue of this method in low-porosity and low-permeability zones is very little change in FZI parameter values between different flow zones, and it causes difficulties in quality classification process. Unit FZI 2 (light blue) and unit FZI 3 (dark blue) are not fully separated, similarly unit FZI 1 dark blue and FZI 4 (yellow). In particular, the low-porosity samples from Well-1 show little variation in different FZI units. Furthermore, there is always some mismatch between well logcalculated and measured porosity, and therefore, FZI from core data will be different than calculated based on well log 


\section{Box Plot by HRA Cluster}

4 clusters

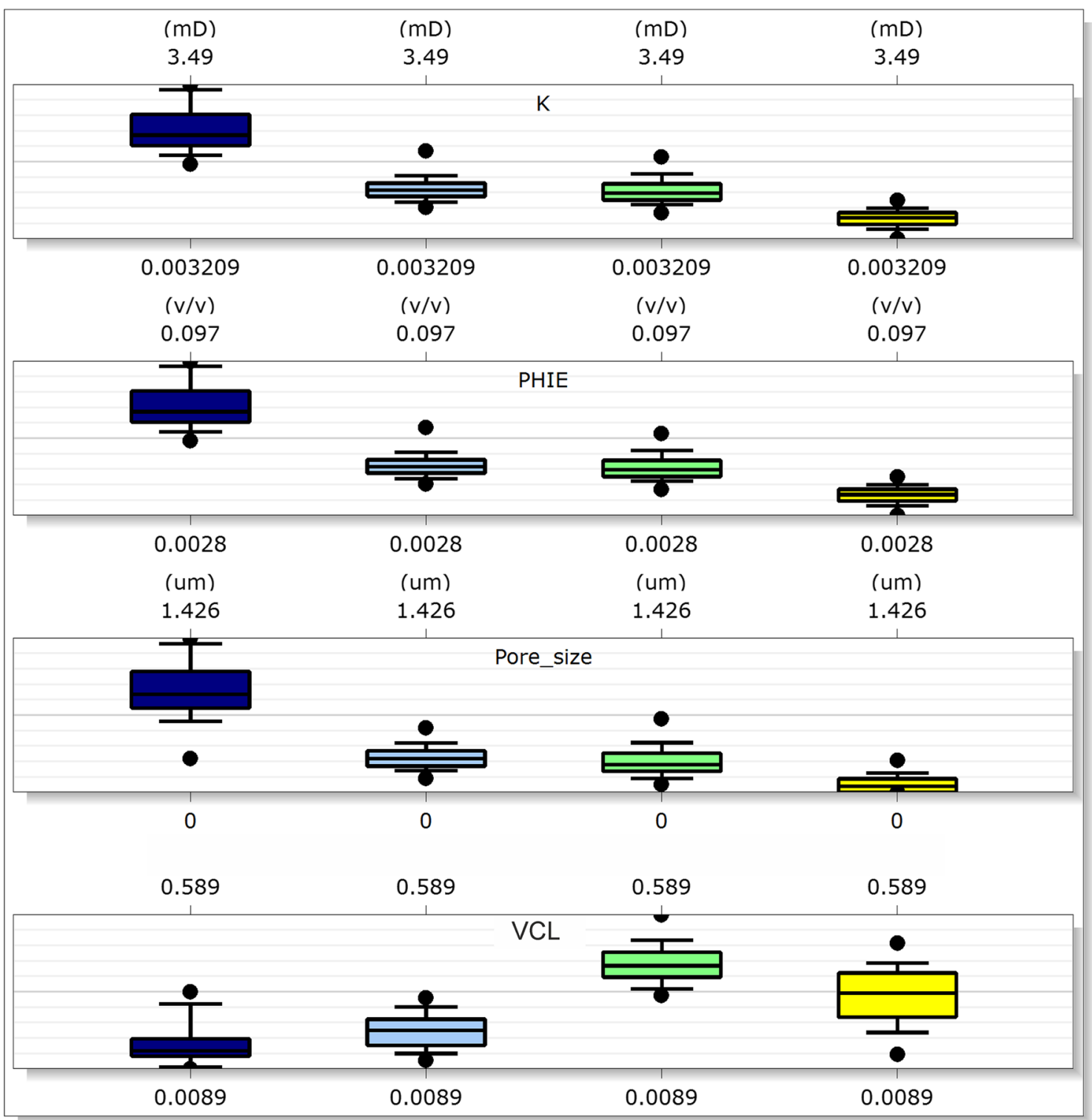

Fig. 6 Variability of input data for each unit presented in box plot. HRA 1 is dark blue, HRA 2 is light blue, HRA 3 is green and HRA 4 is yellow

data. It will be seen, in particular, in Well-2 where fractures are present. In Well-2 (Fig. 10), there are not much changes in flow parameters average values in different units (Fig. 10). That shows FZI discriminator is not a good-quality index in tight formation.

Some conventional reservoirs rocks can successfully be classified in FZI method. However, sensitivity decreases when there is an unusual relation between porosity-permeability or there is no relationship $K$-PHIE due to large amount of small disconnected pores. Nevertheless, this method could be used in each reservoir to obtain accurate permeability curve, which fits much better to core measurements (Fig. 12, track 2). It might be also used to identify the fractured intervals within the reservoir; however, it requires a good representative number of core samples where fracture permeability is measured.

\section{The results obtained from the third classification method}

The units were defined based on Eq. (2). This method takes into account the impact of average pore sizes and amount of 

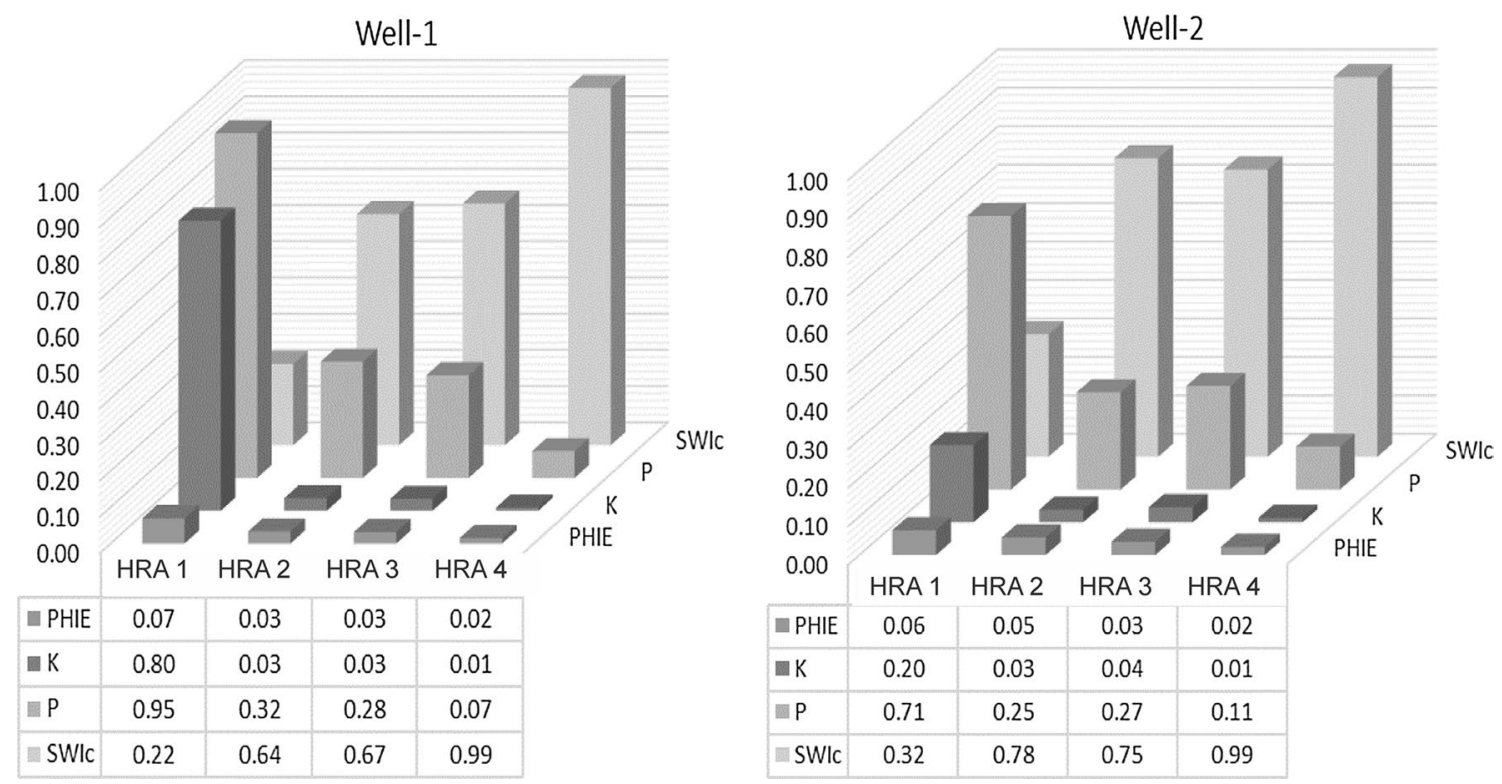

Fig. 7 The average values of flow parameters in subdivided HRA units in Well-1 and Well-2

Table 1 The permeability equations, correlation coefficient $R$, and range of FZI values, for each FZI unit identified in Well-1 and Well-2

\begin{tabular}{lllll}
\hline Well name & FZI units & Permeability equations & $R$ & FZI \\
\hline Well-1 & FZI 1 & $\log 10 \mathrm{~K} 1=2.85 * \log 10$ (PHIE)-2.24 & 0.961 & $2.4<$ FZI $<4$ \\
& FZI 2 & $\log 10 \mathrm{~K} 2=2.83 * \log 10$ (PHIE)-2.73 & 0.954 & $1.1<$ FZI $<2.4$ \\
& FZI 3 & $\log 10 \mathrm{~K} 3=1.82 * \log 10$ (PHIE)-2.83 & 0.569 & $0<$ FZI $<1.1$ \\
Well-2 & FZI 4 & $\log 10 \mathrm{~K} 4=2 * \log 10$ (PHIE)-0.5 & 0.14 & FZI $>4$ \\
& FZI 1 & $\log 10 \mathrm{~K} 1=3.62 * \log 10$ (PHIE)-3.56 & 0.816 & $0.07<$ FZI $<0.15$ \\
& FZI 2 & $\log 10 \mathrm{~K} 1=3.58 \log 10$ (PHIE)-3.92 & 0.959 & $0.04<$ FZI $<0.07$ \\
& FZI 3 & $\log 10 \mathrm{~K} 1=3.32 * \log 10$ (PHIE)-4.12 & 0.873 & $0<$ FZI $<0.04$ \\
& FZI 4 & $\log 10 \mathrm{~K} 1=1.69 * \log 10$ (PHIE)-1.11 & 0.834 & FZI $>0.15$ \\
\hline
\end{tabular}

line in track two is the final permeability curve obtained during FZI unit identification process. Third column shows the average pore size distribution. Forth track contains the values of capillary water saturation (gray color) and mobile fluids saturation (blue). The next three columns (5-7) represent four subdivided units during HRA, FZI, and TRQI classification, respectively. Unit of dark blue is the best quality unit with the highest values of permeability and porosity. Light blue unit is still good-quality tight zone. Unit 3 (green color) is poor-quality unit in TRQI classification. In HRA classification, these units represent the clay inserts and have the highest volume of clay minerals, but its porosity and permeability remain comparable to HRA 2. Yellow color unit is the worst-quality impermeable very tight unit with no accumulation potential in HRA and TRQI classification. In FZI classification, this unit is related to the presence of fractures where despite the low-porosity and low average values of pore sizes, and the measured permeability was high. The azimuth of 


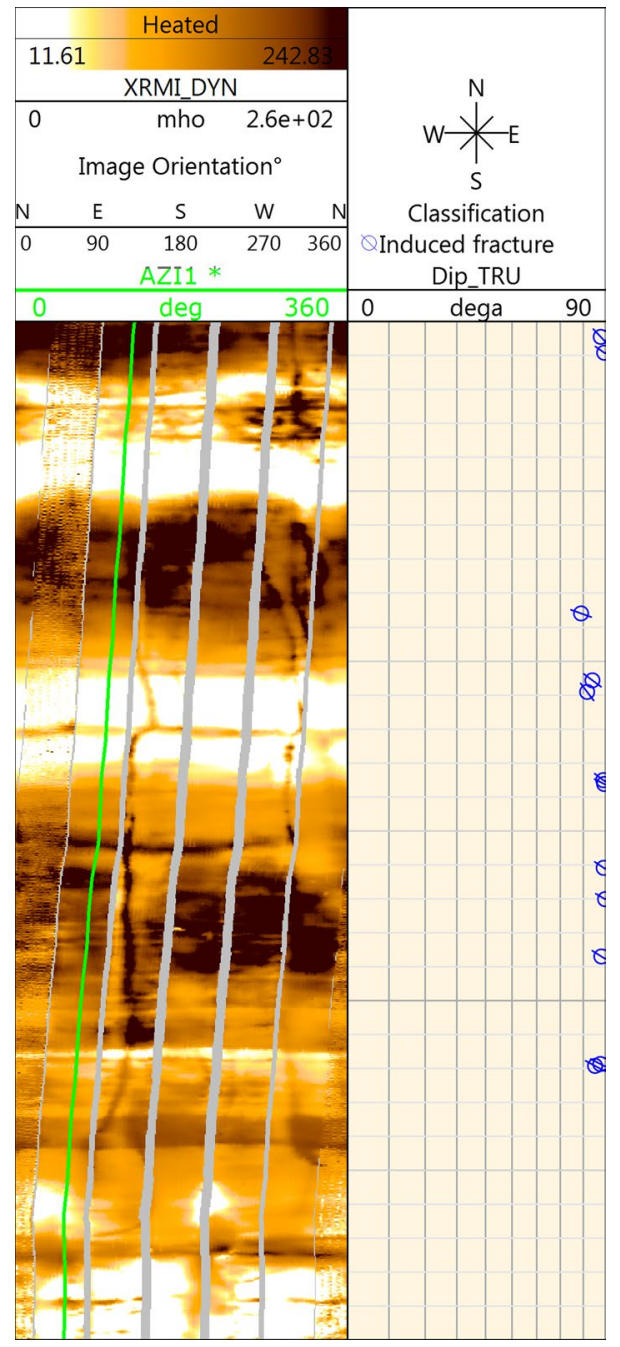

Fig. 8 Drilling-induced fractures seen on XRMI image in Well-2 natural fractures, borehole breakouts, and tensile fractures are presented in the last column.

\section{Fractures versus rock type}

The analysis of XRMI images in Well-1 shows the presence of natural fractures, and the stereonet plot in Fig. 13 shows the fractures assigned to different TRQI units. The interpretation of XRMI images from Well-2 shows the presence of drilling-induced fractures, breakouts, and natural conductive fracture. All kinds of fractures can be economically important. Induced fractures may connect the wellbore to natural fractures that would otherwise not contribute to flow capacity (Crain 1999). Stereonet plot (Fig. 14 on the left) shows all kind of discontinuities seen on the XRMI images in Well-2. The color scale on the stereonet plot is assigned to different types of discontinuities. Stereonet plot on the right side shows all fractures and breakouts assigned to identified FZI units. The stereonet plots presented in Fig. 15 shows all fractures seen in Well-2, with the color scale linked to different HRA units (on the left) and TRQI units on the right. In all classification methods, it can be noticed that most of the drilling-induced fractures and breakouts are related to units 1 and 2 which have the highest porosity and permeability values. These induced fractures normally extend beyond the diameter of the borehole and are potential pathways for vertical gas migration (Holloway 2018). Natural fractures may be important to producibility in tight gas sandstone.

The presence of natural conductive fractures is not strictly linked to one flow unit, but they occur randomly through the whole reservoir interval; they might constitute additional pathways for gas migration but also may increase
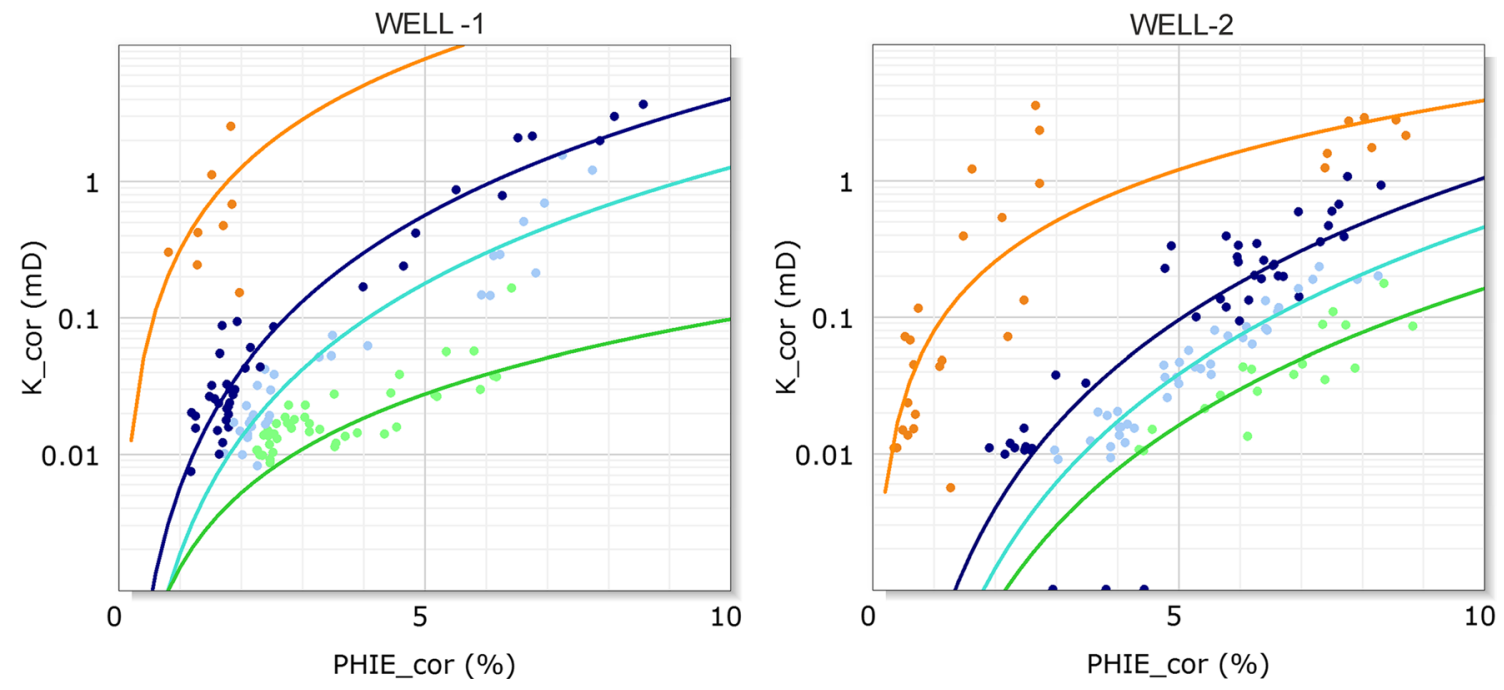

Fig. 9 Permeability-porosity cross-plots for Well 1 and Well-2 with four correlation lines drawn based on FZI values. Dark blue is FZI unit 1, light blue FZI unit 2, green FZI unit 3 and yellow FZI unit 4 
Well-1

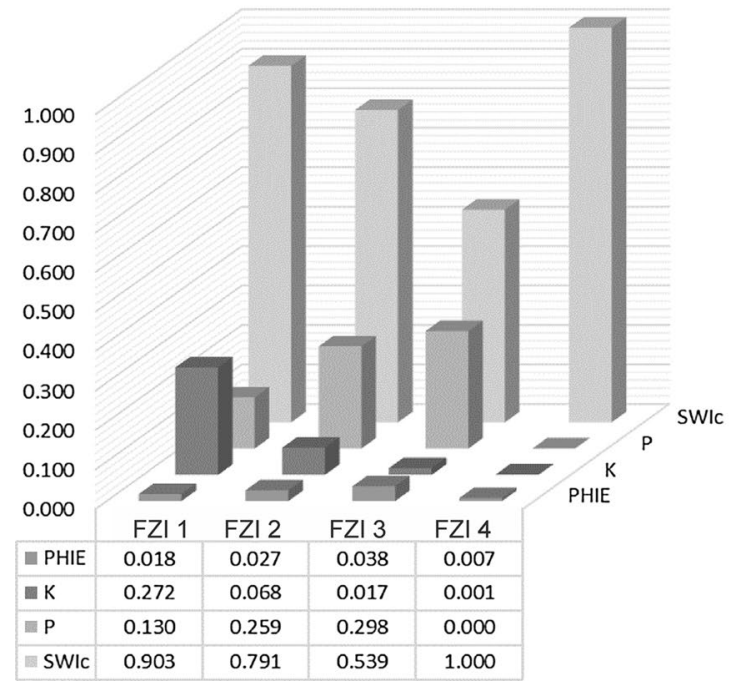

Well-2

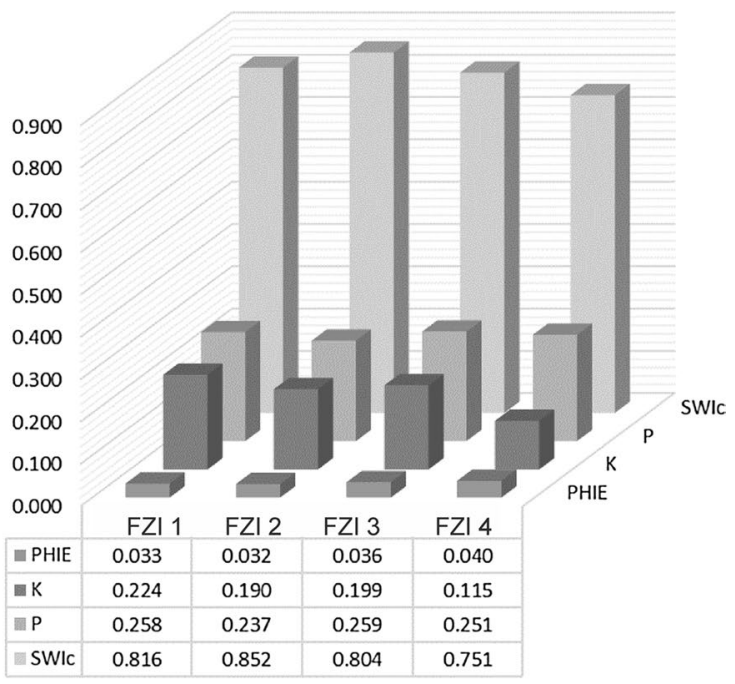

Fig. 10 The average values of flow parameters in subdivided FZI units in Well-1 and Well-2

Table 2 TRQI values for each unit and unit quality description

\begin{tabular}{|c|c|c|}
\hline Units & $\begin{array}{l}\text { TRQI ranges for } \\
\text { both wells }\end{array}$ & Unit quality description \\
\hline TRQI 1 & $>15$ & $\begin{array}{l}\text { Sub-tight sandstones with high permeability and porosity, low con- } \\
\text { tent of capillary water and high size of pores forming the rock pore } \\
\text { space }\end{array}$ \\
\hline TRQI 2 & $3.8-15$ & Sub-tight to tight \\
\hline TRQI 3 & $1-3.8$ & Tight \\
\hline TRQI 4 & $0-1$ & Very tight almost impermeable unit with high level of SWIc \\
\hline
\end{tabular}

Well-1

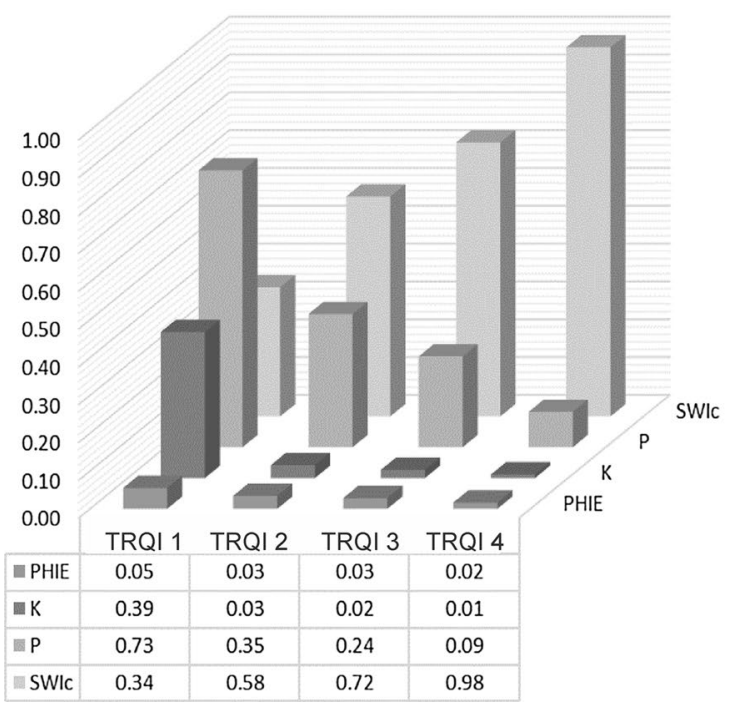

Well-2

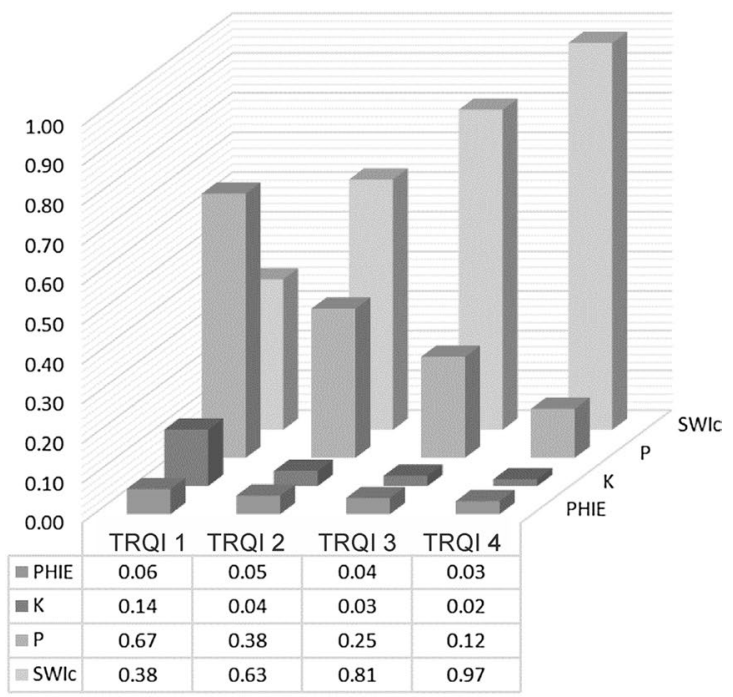

Fig. 11 The average values of flow parameters in subdivided TRQI units in Well-1 and Well-2 

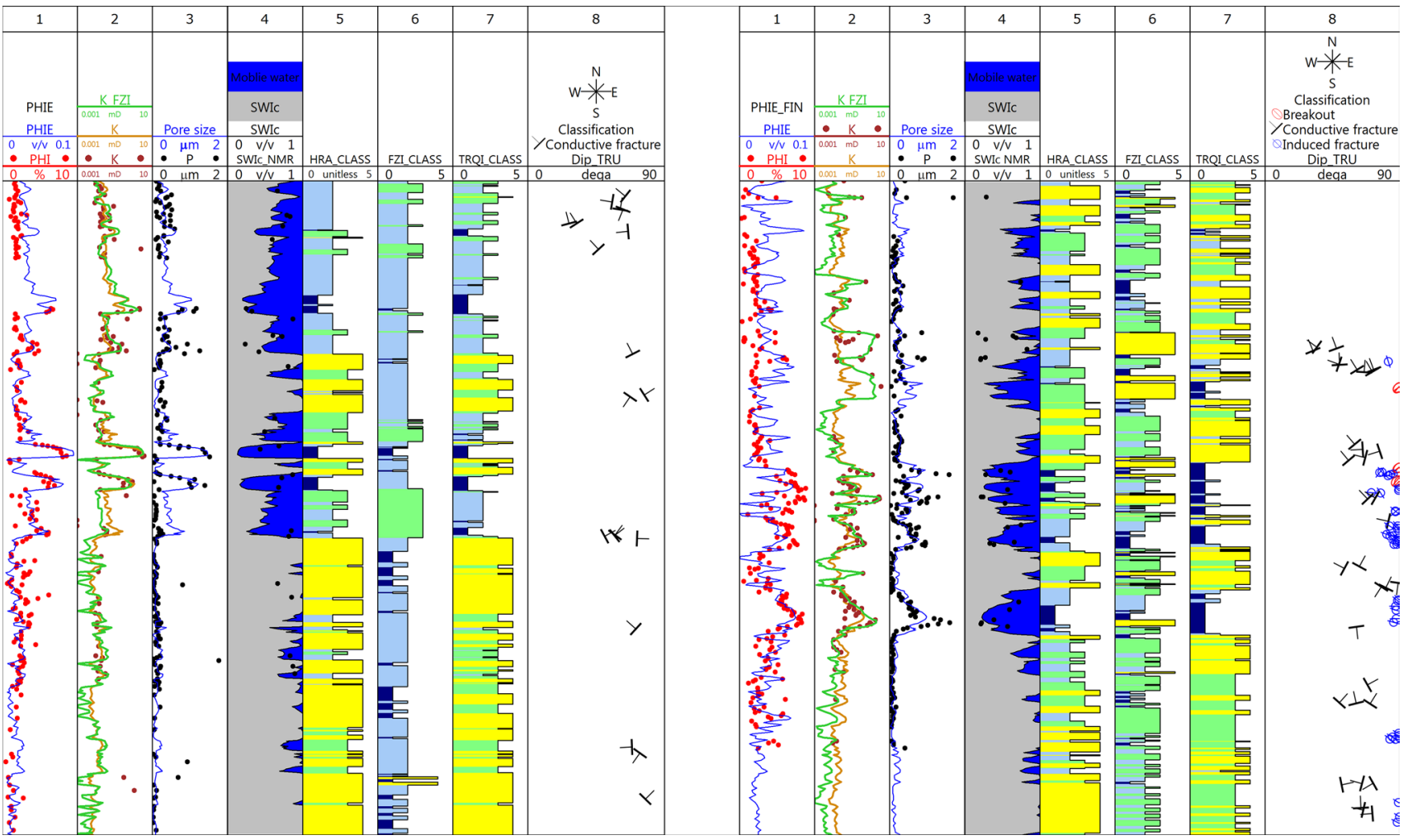

Fig. 12 The results of flow units identification in Well 1 (on the left) and Well-2 (on the right)

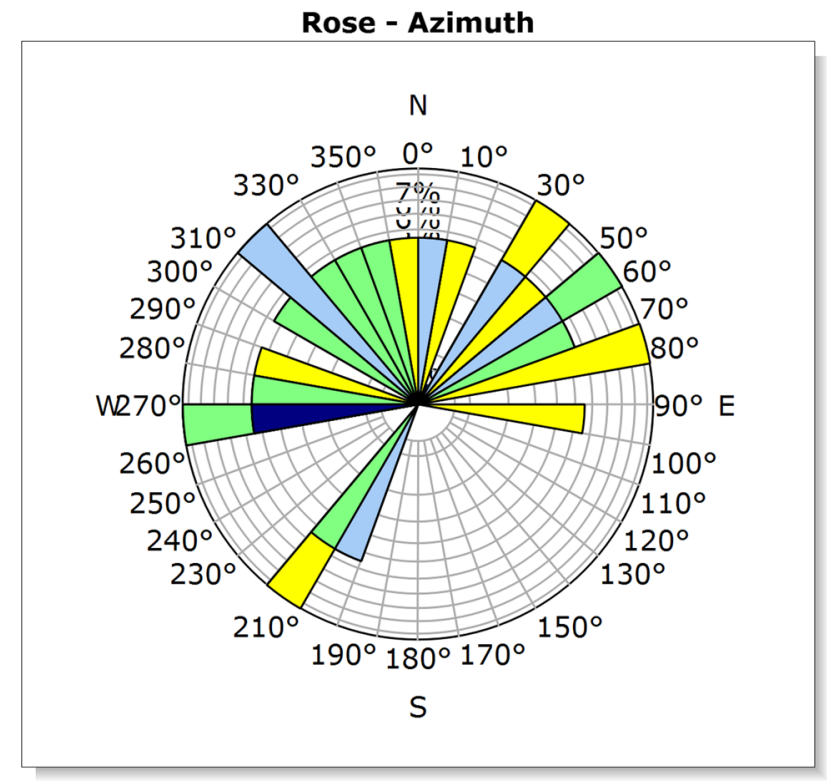

Dip_TRU (dega) / Azimuth (dega)

\section{Simple filter:}

$\square 2$

$\square 3$

$\square 4$

Fig. 13 Natural fractures in Well-1 assigned to different rock units, according to TRQI clustering method. TRQI 1-dark blue, TRQI 2-light blue, TRQI 3-green, TRQI 4-yellow water production (Zee Ma et al. 2016). Even unit FZI 4, which is supposed to be fracture-related, does not seem to be more affected than the other units. It is probably due to the existence of both primary and secondary porosity systems simultaneously through the reservoir. To be able to describe the impact of fracture permeability on the absolute permeability of the rock, more specific laboratory measurements of fracture permeability are required. It is also possible to estimate fracture permeability from XRMI images based on calculated fracture aperture and fracture trace length.

\section{Model comparison and validation}

The assessment of the results obtained from models 1 and 3 were performed by comparing laboratory-measured data of porosity (PHIE_cor), permeability (K_cor), and pore sizes (P_cor) with the porosity (PHIE), permeability (K), and pore sizes $(P)$ from well log data, assigned to four different units. Figure 16 presents the core data assigned to HRA units, and Fig. 17 presents the core data classification according to TRQI method. Dark blue represents unit 1, light blue is unit 2 , green color is unit 3 , and yellow is unit 4 . As can be noticed in Fig. 15, porosities above 4\% and permeabilities above $0.03 \mathrm{mD}$ fall into unit 1 of HRA classification. Unit 2 compromises wide range of porosity and permeability 

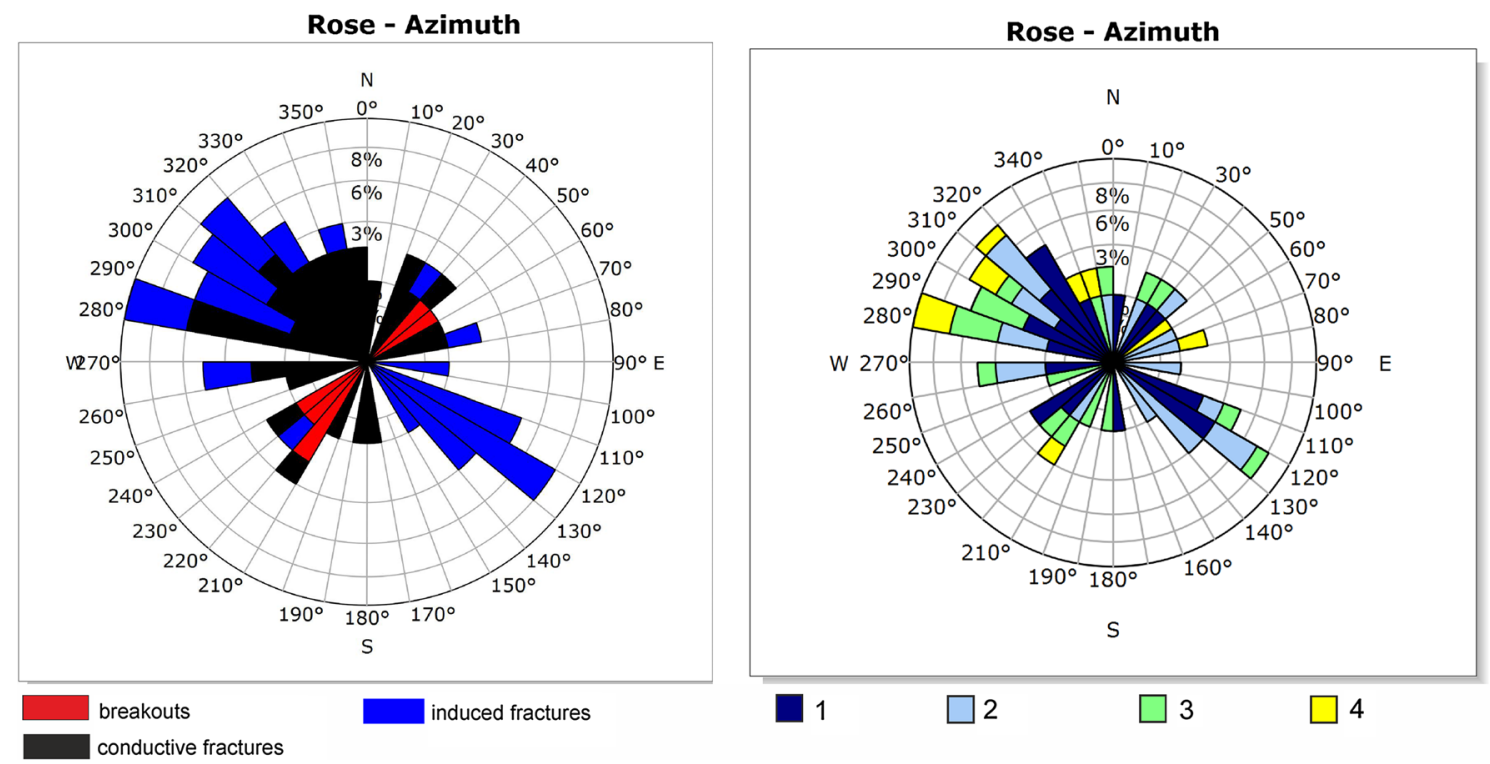

Fig. 14 Types of fractures present in Well-2 (on the left). Fractures assigned to different units in Well-2 according to FZI classification method (on the right; FZI 1-dark blue, FZI 2-light blue, FZI 3-green, FZI 4-yellow

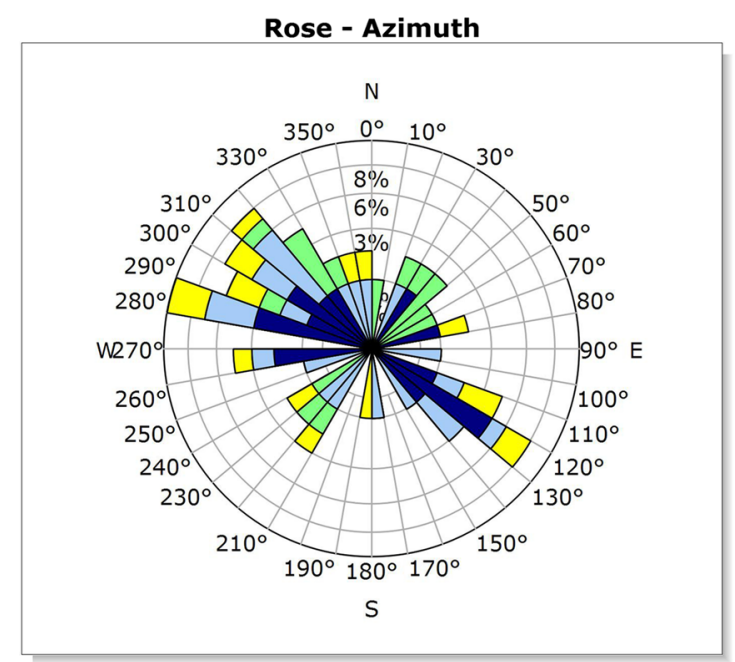

Dip_TRU (dega) / Azimuth (dega)

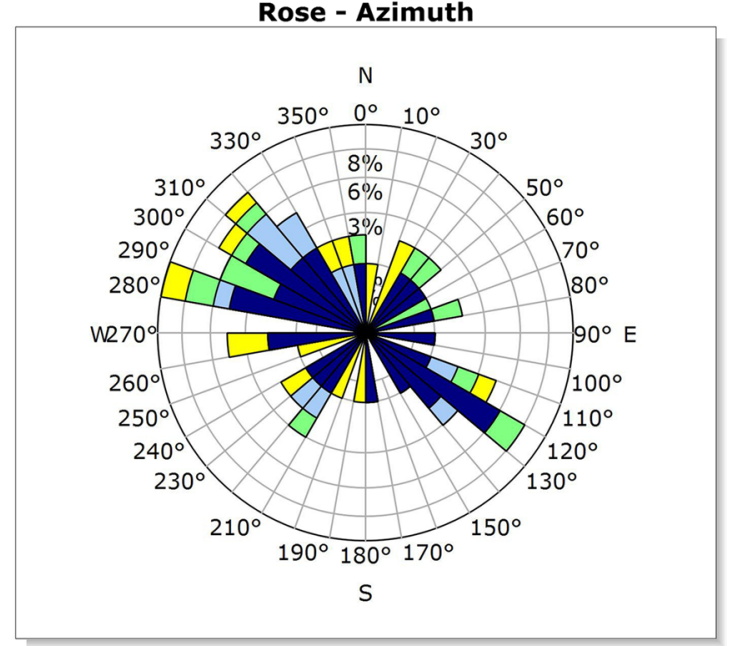

Dip_TRU (dega) / Azimuth (dega)

Fig. 15 Fractures assigned to different units in Well-2; according to HRA classification method (on the left) and according to TRQI (on the right)

data with pore sizes generally from 0.2 to $0.5 \mu \mathrm{m}$. It can be noticed there is a stronger relationship between permeability and pore sizes than between porosity and permeability. Unit 4 is represented by samples of very low permeability $0.02 \mathrm{mD}$ and pore sizes up to $0.4 \mu \mathrm{m}$. HRA unit 3 is represented by small number of samples, and it is hard to find trends of parameters changing for this group. Outliers observed on cross-plots are probably related to secondary (fracture) permeability, scale problem, or errors during measurement process. This comparison should only show the trends of changes in different units. The last classification methods show better separation of good-quality units 1 and 2 from poor quality units 3 and 4 in which porosity generally does not exceed $5 \%$, permeability is below $0.03 \mathrm{mD}$, and pore sizes are smaller than $0.4 \mu \mathrm{m}$. Both first and third methods of classification can be used in tight reservoirs rock typing process. However, the input data need core calibration, and these methods give better results when there are no 


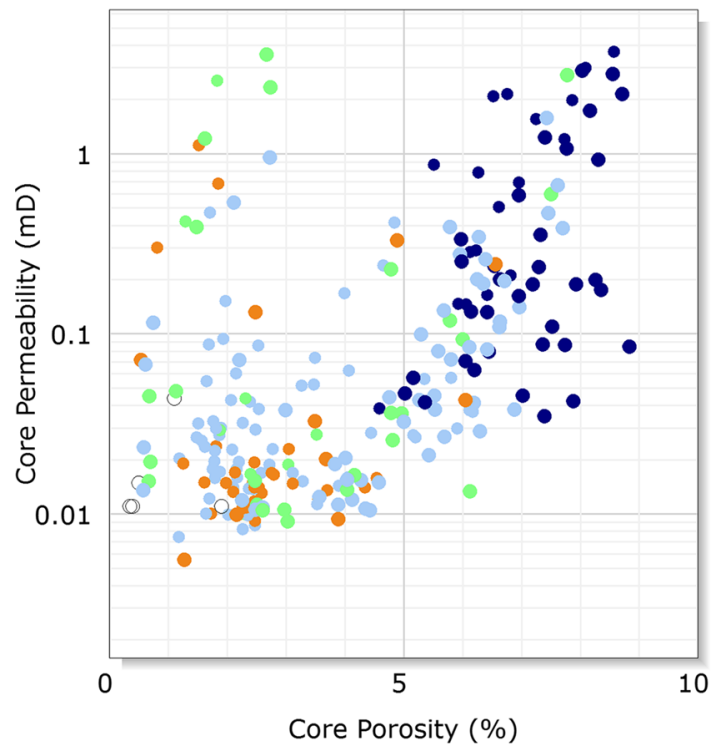

Fig. 16 The values of core-measured porosity and permeability (on the left) and the values of core permeability correlated with pore sizes (on the right) assigned to four defined HRA units, colors mean

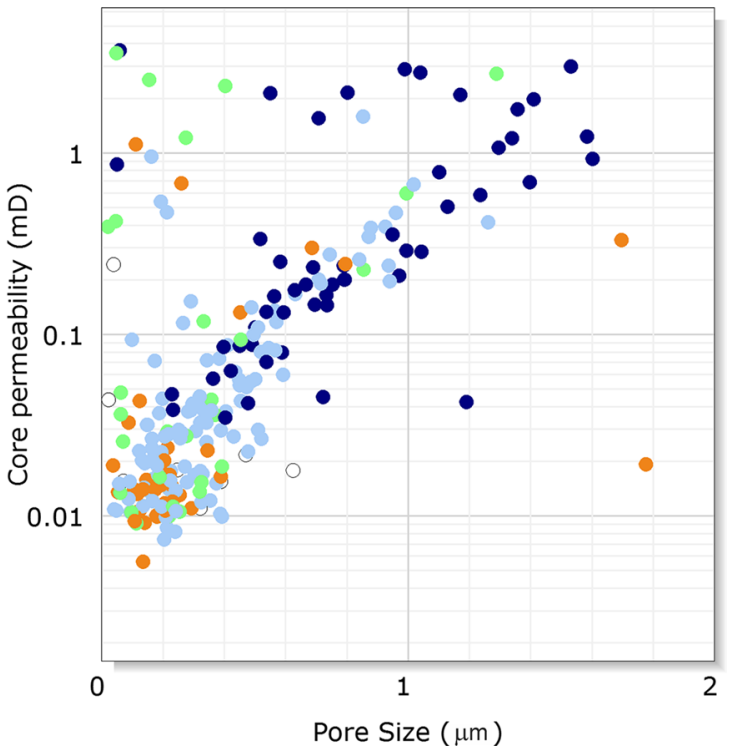

HRA units, HRA 1 is dark blue, HRA 2 is light blue, HRA 3 is green, and HRA 4 is orange
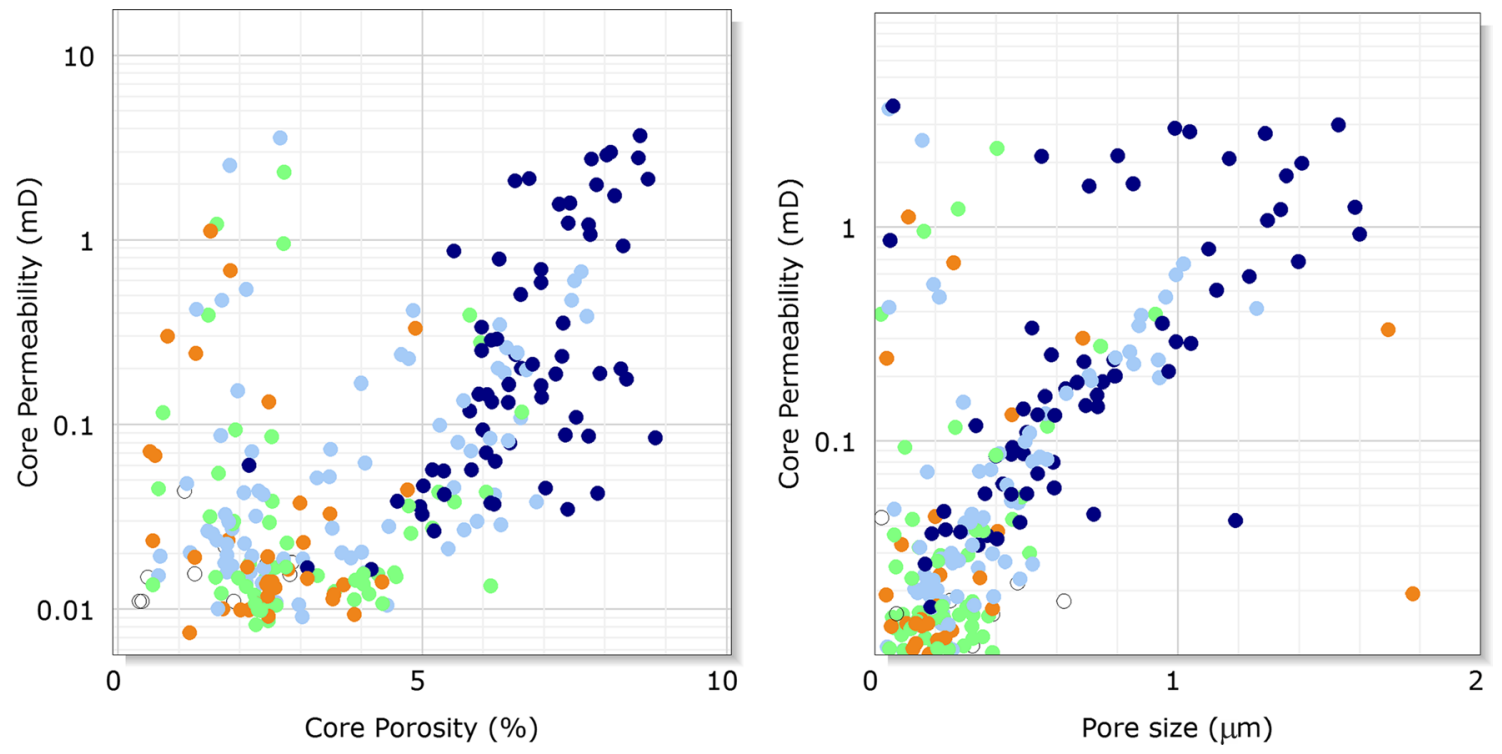

Fig. 17 The values of core-measured porosity and permeability (on the left) and the values of core permeability correlated with pore sizes (on the right) assigned to four defined TRQI units

fractures in the reservoirs. The presence of crack and fissure disturbs the relationship between porosity and permeability and causes problem during input data calibration.

The validity of the second model is checked at three different levels: the core measurements, the well log values of PHIE_cor, K_cor, P_cor, and SWIc_cor for each subdivided FZI unit, also histograms of PHIE, $\mathrm{K}$, and pore sizes distribution which were made to check the ranges of values for each FZI unit. At the core data level, the FZI prediction model as given by Eq. (1) is validated by comparing the calculated permeability based on the FZI method to the measured permeability at the cored depths. The good match was observed. Then FZI was calculated based on well log data. Four units were identified, and the average values of PHIE, $K, P$, and SWIc were calculated. Unfortunately, the validation of this method fails at this point. There was no 
consistency in parameters variations in different units. The histograms of permeability and porosity presented in Fig. 18 also show that each FZI unit compromises the whole range of porosity and permeability, which means that, for example, FZI unit 1 that should represent sub-tight flow unit with the highest PHIE and $\mathrm{K}$ provides the ranges of $K$ of almost impermeable rocks, $0.001-3.5 \mathrm{mD}$, and porosity range from 0.5 to $10 \%$. The reason why this method may not be appropriate for tight formation is the dependence between porosity and permeability in tight formation. The porosity may be reasonably high $4-5 \%$, but if the pores are not connected, they will have no impact on permeability values. At this point, it would be better to consider the relationship between permeability and pore size distribution. When two more factors were taken into account, pore size distribution and the capillary water saturation, much better results were achieved. HRA clustering method enable good separation of permeability, porosity, and pore size ranges for HRA 1 and HRA 4 units (Fig. 19). HRA unit 2 and 3 cover similar porosity, permeability, and pore size range and could be treated as one tight unit. The only difference between those two units is that HRA 3 has higher clay volume content and might represent clay inserts.
The last method of classification shows a similar overlap of the data points for a large range of pore sizes and permeabilities as the HRA method. The units are not distinctly separated (Fig. 20). The last very tight impermeable unit TRQI 4 has similar properties as TRQI 3, but it covers wide range of porosities from 0.4 to $5 \%$. It represents the intervals where despite the high porosities of $4-5 \%$, permeability and pore sizes remain low, which is related to zones where part of pores are disconnected and has no impact on the permeability values.

\section{Conclusions}

We took three different approaches to develop an index for characterization of tight sandstone formation. Two of three tested methods 1 and 3 prove to be proper methods of rock quality discriminator in low-porosity and low-permeability formations. The methods help to identify the intervals of better flow properties, within multilayered tight reservoir and define depths to be a subject of the future fracturing process. Tight formations show better dependence between permeability and pore size distribution than between permeability
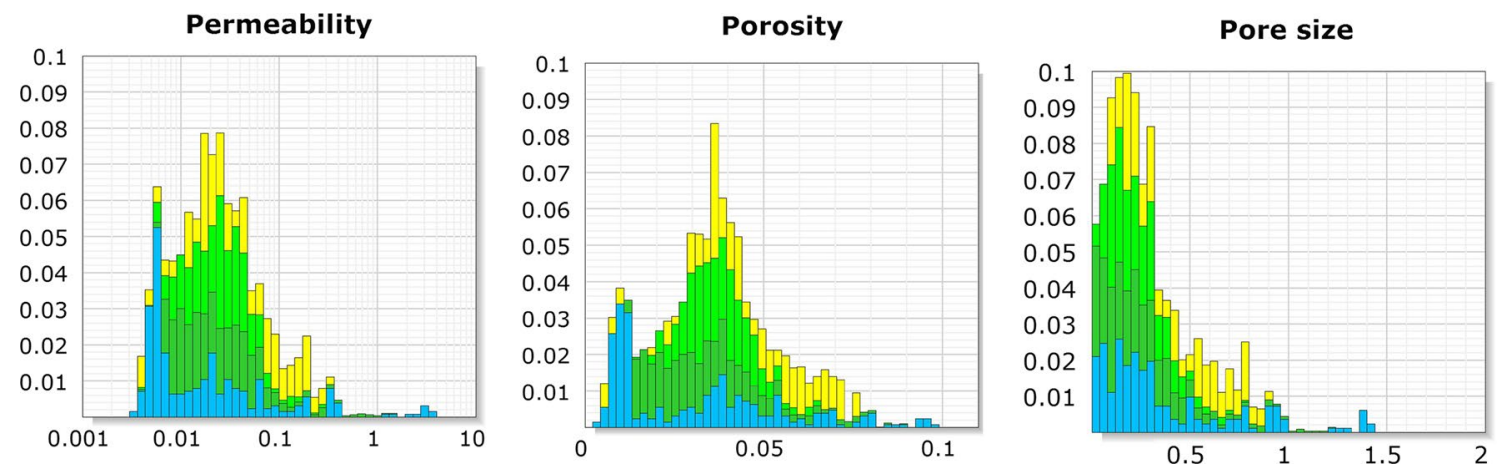

Fig. 18 Histograms of permeability, porosity and pore sizes for identified FZI units. Blue color is FZI 1, dark green is FZI 2, light green FZI 3 , yellow FZI 4 (Well-1 and Well-2)
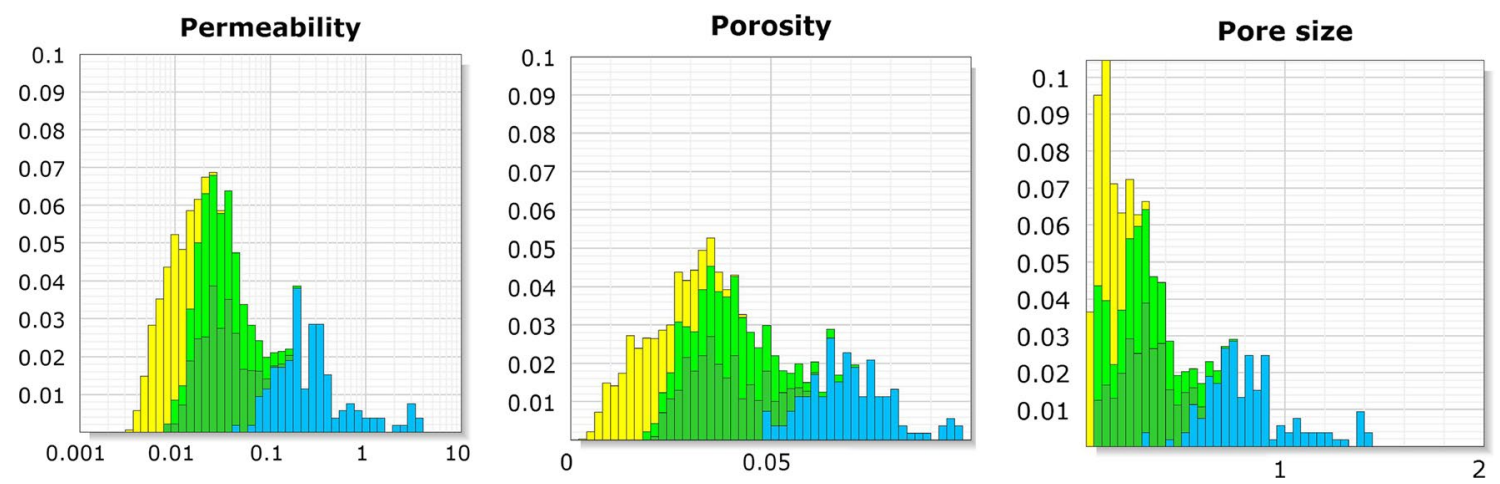

Fig. 19 Histograms of permeability, porosity and pore sizes for identified HRA units. Blue color is HRA 1, dark green is HRA 2, light green HRA 3, yellow HRA 4 (Well-1 and Well-2) 

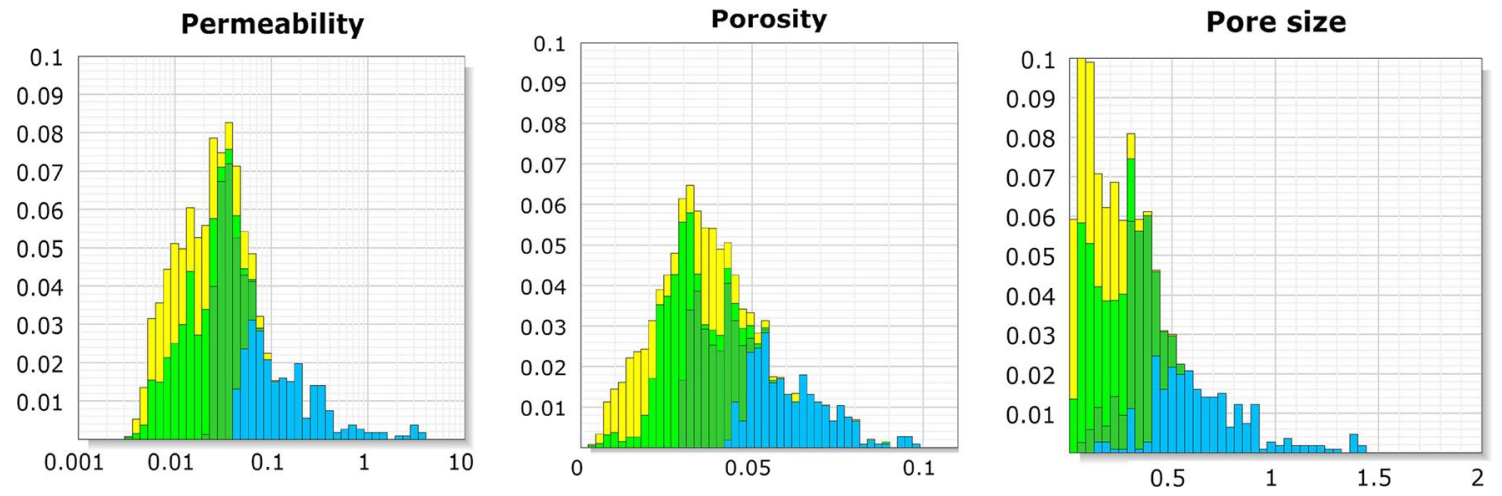

Fig. 20 Histograms of permeability, porosity and pore sizes for identified TRQI units. Blue color is TRQI 1, dark green is TRQI 2, light green TRQI 3, yellow TRQI 4 (Well-1 and Well-2)

and porosity. The second method is not appropriate for the analyzed low-porosity and low-permeability reservoir. Therefore, certain rock type can comprise entire range of porosity and permeability, which is not physically reliable. However, it is a great method for accurate core-calibrated permeability prediction. The another reason why FZI method fails is the presence of fractures, and then mismatch between calculated and measured porosity can be observed, and FZI calculated from measured porosity and permeability will be different from these calculated from well log data. However, this method might be used to calculate the input permeability for other rock qualification methods. A comparison between HRA, FZI, and TRQI unit results was established. The comparison showed that the HRA and TRQI results were often in better agreement with the petrophysical evaluation of analyzed reservoir. Also, good match between subdivided units and core-measured data was observed. It was observed that FZI method failed in identification of flow units in low-permeability formation. FZI method although gives good results in conventional reservoirs is probably not dedicated to unconventional, tight formations. Although core measurements are of great importance during wellbore interpretation, they may underestimate the porosity and permeability in dual-porosity reservoir. Core measurements of secondary porosity and permeability are difficult as it is hard to estimate the real, in situ fracture aperture and the length of cracks. The well log data measure the total porosity, including disconnected pores, and provide better estimation of porosity and permeability in fractured reservoir. In this kind of reservoirs, it is better to perform rock typing based on well log input data as it will probably give more accurate results. FZI unit method was set up on core measurements and applied to well logs which do not provide satisfactory results. The inputs were core-calibrated just to obtain the general trend of parameters variations.

Both HRA and TRQI method qualify the reservoir rock based on well log data, but only a marginally better separation seems to be provided by the proposed TRQI method with respect to HRA method. Units 2, 3, and 4 more or less overlap in both methods, and they are not distinctly separated. Due to the necessity of having the additional variable SWIc to be able to use TRQI method which gives only slightly better results, it seems to be more practical to perform rock typing based on HRA clustering method or maybe just simple $K$-mean clustering algorithm. Moreover, in this elaboration, capillary water content (SWIc) was estimated using NMR laboratory measurements which are not often performed in wells, and calculation of capillary water content based only on well log data might be burdened with the risk of a significant error. Porosity, permeability, and pore size distribution, which were used as an inputs in the HRA classification method, can be calculated from well log data and calibrated with core-measured PHIE_cor, K_cor, and pore sizes (MIP) which are commonly measured in tight reservoirs.

Acknowledgements The author would like to thank Polish Oil and Gas Company (PGNiG S.A.) for the permission to use data that helped in writing this paper. The author would like to thank the reviewers who kindly reviewed the manuscript and provided valuable suggestions and comments.

\section{Compliance with ethical standards}

Conflict of interest The author states that there is no conflict of interest.

Open Access This article is distributed under the terms of the Creative Commons Attribution 4.0 International License (http://creativeco mmons.org/licenses/by/4.0/), which permits unrestricted use, distribution, and reproduction in any medium, provided you give appropriate credit to the original author(s) and the source, provide a link to the Creative Commons license, and indicate if changes were made. 


\section{References}

Alhashmi NF, Torres K, Faisal M, Segura Cornejo V, Bethapudi BP, Mansur S, Al Rawahi AS (2016) Rock typing classification and hydraulic flow units definition of one of the most prolific carbonate reservoir in the onshore Abu Dhabi, Abu Dhabi Co For Onshore Petroleum Operations Ltd

Aliakbardoust E, Rahimpour-Bonab H (2013) Integration of rock typing methods for carbonate reservoir characterization. J Geophys Eng. https://doi.org/10.1088/1742-2132/10/5/055004

Aliyev E, Saidian M, Prasad M, Russell B (2016) Rock typing in tight gas sands: a case study in lance and Mesaverde formations from Jonah field. J Nat Gas Sci Eng 33:1260-1270. https://doi. org/10.1016/j.jngse.2015.12.045

Amaefule JO, Altunbay M, Tiab D, Kersey DG, Keelan D (1993) Enhanced reservoir description: using core and log data to identify hydraulic (flow) units and predict permeability in uncored intervals/wells. Paper SPE 26436 presented at the 1993 SPE annual technical conference and exhibition in Houston

Amann A, Krooss BM (2015) Effective gas permeability of tight gas sandstones as function of capillary pressure-a non- steady state approach. Geofluids. https://doi.org/10.1111/gfl.12155

Berg RR (1986) Reservoir sandstones. Prentice-Hall, Inc., Englewood Cliffs

Bliefnick DM, Kaldi JG (1996) Pore geometry; control on reservoir properties, walker creek field, Columbia and Lafayette counties, Arkansas. Am Assoc Pet Geol Bull 80:1027-1044

Crain ER (1999) Crain petrophysical handbook. https://www.spec2000. net. Accessed 24 Apr 2019

Doveton JH (1994) Geologic log analysis using computer methods. AAPG computer applications in geology. American Association of Petroleum Geologists, Tulsa

Duenas C (2014) Understanding rock quality heterogeneity of Montney Shale Reservoir. Pouce Coupefield, Alberta, Canada

Dullien FAL (1992) Porous media: fluid transport and pore structure. Academic Press, New York

Guo G, Diaz MA, Paz F, Smalley J, Waninger EA (2005) Rock typing as an effective tool for permeability and water-saturation modeling: a case study in a clastic reservoir in the Oriente Basin. In: SPE annual technical conference and exhibition held in Dallas, Texas, USA

Holloway MD (2018) Fracking: further investigations into the environmental considerations and operations of hydraulic fracturing, 2nd edn. Scrivener Publishing, New York

Hong L, Fuqiang L, Liang C, Chao L, Jie L, Heping Y (2017) Research on evaluation method for water saturation of tight sandstone in Suxi region. In: IOP conference series earth and environmental science, vol 64, no (1), p 012040

Hotelling H (1933) Analysis of a complex of statistical variables into principal components. J Educ Psychol 24(6):417-441. https://doi. org/10.1037/h0071325

Ilkhchi RK, Rezaee R, Harami RM, Friis M, Ilkhchi AK (2014) An integrated rock typing approach for unraveling the reservoir heterogeneity of tight sands in the Whicher Range field of Perth Basin. Western Australia J Geol 4(8):373
Jiang Z, Li Z, Li F, Pang X, Yang W, Liu L, Jiang F (2015) Tight sandstone gas accumulation mechanism and development models. Pet Sci 12(4):587-605

Keelan DK (1982) Core analysis for aid in reservoir description. Society of Petroleum Engineers, Richardson. https://doi. org/10.2118/10011-PA

Laškova LN (1987) The Cambrian: oil fields of the Baltic region. Mokslas, Vilnius, pp 10-22

Molenaar N, Cyziene J, Sliaupa S (2007) Quartz cementation mechanisms and porosity variation in Baltic Cambrian sandstones. Sediment Geol 195(3-4):135-159. https://doi.org/10.1016/j.sedge o.2006.07.009

Nelson PH (2009) Pore throat sizes in sandstones, tight sandstones, and shales. AAPG Bull 93:329-340

Pearson KFRS (1901) LIII on lines and planes of closest fit to systems of points in space. Lond Edinb Dublin Philos Mag J Sci 2(11):559-572. https://doi.org/10.1080/14786440109462720

Puskarczyk E, Krakowska P, Jędrychowski M, Habrat M (2018) A novel approach to the quantitative interpretation of petrophysical parameters using nano-CT: example of Paleozoic carbonates. Acta Geophys 66:453. https://doi.org/10.1007/s11600-018-0219-x

Radlinski AP, Ioannidis MA, Hinde AL, Hainbuchner M, Baron M, Rauch H, Kline SR (2004) Angstrom-to-millimeter characterization of sedimentary rock microstructure. J Colloid Interface Sci 274:607-612

Sikorska M, Pacześna J (1997) Quartz cementation in Cambrian sandstones on the background of their burial history (Polish part of the East European Craton). Geol Q 41(3):265-272

Speight JG (2017) Deep shale oil and gas. CD\&W, Laramie

Timur A (1968) An investigation of permeability, porosity, and residual water saturation relationships. In: The 9th SPWLA annual logging symposium, paper J

Vavra CL, Kaldi JG, Sneider RM (1992) Geological applications of capillary pressure: a review. Am Assoc Pet Geol Bull 76:840-850

Wyllie MRJ, Rose WD (1950) Some theoretical considerations related to the quantitative evaluation of the physical characteristics of reservoir rocks from electrical log data. Pet Trans AIME 189:105-118

Zawisza L, Nowak J (2012) Metodyka określania parametrów filtracyjnych skał na podstawie kompleksowej analizy danych geofizyki otworowej, wydawnictwa AGH (in Polish)

Zee Ma Y, Moore WR, Gomez E, Clark WJ, Zhang Y (2016) Tight gas sandstone reservoirs, part 1: overview and lithofacies. In: Ma YZ, Holditch S (eds) Handbook of unconventional resources. Schlumberger, Denver, pp 405-427

Zhang J, Nie X, Xiao S, Zhang C, Zhang C, Zhang Z (2018) Generating porosity spectrum of carbonate reservoirs using ultrasonic imaging log. Acta Geophys 66:191. https://doi.org/10.1007/s1160 0-018-0134-1

Zhu L, Zhang C, Zhang C, Zhou X, Wang J, Wang X (2018) Application of multiboost-KELM algorithm to alleviate the collinearity of log curves for evaluating the abundance of organic matter in marine mud shale reservoirs: a case study in Sichuan Basin. China Acta Geophys 66:983. https://doi.org/10.1007/s11600-018-0180-8 